\title{
Correction to: Optimism and social support as contributing factors to spirituality in Cancer patients
}

\author{
Laura Ciria-Suarez ${ }^{1}$ (D) - Caterina Calderon ${ }^{1}$ (D) - Ana Fernández Montes ${ }^{2}$ (D) $\cdot$ Mónica Antoñanzas $^{3}$ (D) \\ Raquel Hernández ${ }^{4}$ (D) Jacobo Rogado ${ }^{5}$ (D) Vilma Pacheco-Barcia ${ }^{6}$ (D) - Elena Asensio-Martínez ${ }^{7}$ (D) \\ María Palacín-Lois ${ }^{8}$ (D) Paula Jimenez-Fonseca ${ }^{9}$ (D)
}

Published online: 20 March 2021

(C) Springer-Verlag GmbH Germany, part of Springer Nature 2021

\section{Correction to: Supportive Care in Cancer} https://doi.org/10.1007/s00520-020-05954-4

The original version of this paper unfortunately contained three errors:

- Vilma Pacheco-Barcia: the "c" was missing

- Elena Asensio-Martinez: this name had a spare " $n$ "

- Raquel Hernández: the correct affiliation is Hospital Universitario de Canarias, Tenerife.

Publisher's note Springer Nature remains neutral with regard to jurisdictional claims in published maps and institutional affiliations.

The online version of the original article can be found at https://doi.org/ $10.1007 / \mathrm{s} 00520-020-05954-4$

Laura Ciria-Suarez

laura.ciria.suarez@gmail.com

Caterina Calderon

ccalderon@ub.edu

Ana Fernández Montes

afm1003@hotmail.com

Mónica Antoñanzas

moni_ab@msn.com

Raquel Hernández

raquel_hsg@hotmail.com

\author{
Jacobo Rogado \\ jacobo.rogado@gmail.com \\ Vilma Pacheco-Barcia \\ vilmapbarcia@yahoo.es \\ Elena Asensio-Martínez \\ helenasensio@yahoo.es \\ María Palacín-Lois \\ mariapalacinlois@ub.edu \\ Paula Jimenez-Fonseca \\ palucaji@hotmail.com
}

Extended author information available on the last page of the article 


\section{Affiliations}

\section{Laura Ciria-Suarez $^{1}$ (D) $\cdot$ Caterina Calderon $^{1}$ (D) $\cdot$ Ana Fernández Montes $^{2}$ (D) Mónica Antoñanzas ${ }^{3}$ (D) Raquel Hernández ${ }^{4}$ (D) - Jacobo Rogado ${ }^{5}$ (D) - Vilma Pacheco-Barcia ${ }^{6}$ (D) - Elena Asensio-Martínez ${ }^{7}$ (D) María Palacín-Lois ${ }^{8}$ (D) Paula Jimenez-Fonseca ${ }^{9}$ (D)}

1 Department of Clinical Psychology and Psychobiology, Faculty of Psychology, University of Barcelona, Passeig de la Vall d'Hebron, 171, 08035 Barcelona, Spain

2 Department of Medical Oncology, Complejo Hospitalario de Orense, Orense, Spain

3 Department of Medical Oncology, Hospital Universitario Clínico San Carlos, Madrid, Spain

4 Department of Medical Oncology, Hospital Universitario de Canarias, Tenerife, Spain
5 Department of Medical Oncology, Hospital Universitario Infanta Leonor, Madrid, Spain

6 Department of Medical Oncology, Hospital Universitario Central de la Defensa "Gómez Ulla”, Madrid, Spain

7 Department of Medical Oncology, Hospital Universitario General de Elche, Alicante, Spain

8 Department of Social and Quantitative Psychology, Faculty of Psychology, University of Barcelona, Barcelona, Spain

9 Department of Medical Oncology, Hospital Universitario Central de Asturias, ISPA, Oviedo, Spain 